\title{
Ask the young about the future
}

THE House of Commons Subcommittee's examination of the future of scientific research in British universities seems in imminent danger of falling apart-not through any violent centrifugal tendencies of its members, but because a growing sense of boredom is beginning to surround its missions. This past week, Sir Sam Edwards, Chairman of the Science Research Council, and Sir Fred Stewart, Chairman of the Advisory Board for the Research Councils, two of the men most central to policy-making in science, dourly defended the present system against some tepid questioning, and once more one wondered why we were all there.

Part of the reason for the lack of enthusiasm is that everyone knows that the education and science sector is suffering heavily from the ravages of inflation, and it is thus no time for reasonable men to start bickering among themselves. And the Rothschild reorganisations are too recent in people's memories for there to be much interest in another round of fundamental changes.
So what can the committee profitably do? It could switch its attention to the young students who are potentially a driving force in science in the 1980s. Two questions about them are surely worth extended investigation. First, are they going to continue to desert the physical sciences in large numbers? And, second, what in the educational system leads to the alienation between pure and applied science, which is an undoubted contributor to Britain's poor performance in converting research into development and production? The committee has shown more than a passing interest in this latter issue and might find it a more congenial question, and certainly one with major economic implications. Fiddling with the dual-support system and the structure of the Science Research Council can at most have marginal benefits in comparison, although a detailed look at the alienation problem might well lead, in the longer term, to the fundamental changes which nobody seems keen to contemplate at present.

\section{Is there money still for tea?}

IN recent months, the Department of Energy has been stepping up its campaign to persuade the British public to save energy. "It's everybody's baby. The man who drives alone to work. The boiler-minder who could get more out of his boiler. The housewife who lets her kettle boil away while she chats on the phone. Just by being careful, you can save your own money-and millions for Britain." And in another advertisement a kettle is shown with pound notes steaming out its spout.

Our back-of-the-envelope calculations say this. Britons drink some $2 \times 10^{8}$ cups of tea or coffee daily, of which half come from kettles, each kettle producing two cups, say. Of these $5 \times 10^{7}$ kettles, perhaps half have whistles or automatic cut-outs. Further, of the remainder only about $10 \%$ are kept boiling for any substantial period-let us say on average one minute. Thus British kettles boil unnecessarily for $2.5 \times 10^{6}$ minutes daily. This wastes roughly $10^{5}$ kilowatthours of energy every day. This costs the foolish housewives of Britain $£ 1,500$ a day or an average of $0.015 \mathrm{p}$ per family.

Hardly pounds streaming out of each kettle, you may say, but worth saving nevertheless. But it costs money and it uses up energy to run a publicity campaign. Advertisers measure success at the fractions of a percent level-a campaign that persuaded $1 \%$ of the population to change its ways would have been remarkably successful. At stake are thus anly $10^{3}$ kilowatt-hours of energy or the colossal sum of $£ 15$ a day-although the steam heats up the room and thus for at least half of the year might be deemed a good thing.

We haven't dared ask the department how much this particular advertisement has cost but it must be several thousand pounds-and in the process energy has been consumed in printing it, distributing it and raising it on to a placard.

Ironically, really worthwhile rather than trifling savings are possible when boiling a kettle. Few measure the water into the kettle and as a result an enormous amount of water is raised to the boil and then not used. It is left as an exercise for the reader to determine how much the department could have saved-then to devise an appropriate slogan.

Similar arguments can also be applied to domestic hotwater systems. Lagging a hot-water tank is fine, and the Department of Energy rightly points out that considerable savings of money and energy can be made in this way, but how many people heat their domestic hot water for unnecessarily long periods in the summer, and indeed how many people have hot-water tanks that are too big for their requirements? 